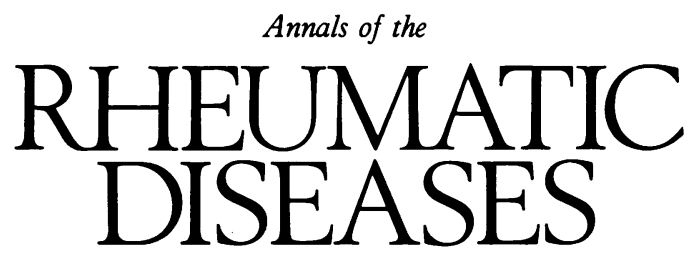

\title{
Forewords
}

Mark Twain's observation about the long term effects of soap and education appeals to our common sense, but it is difficult to assess the true influence of these simple processes on society. The same is true in rheumatology. Most of us believe in the benefits of improving the rheumatological knowledge of doctors and patients, but it is difficult to prove that education is effective.

What do patients expect from their rheumatologist? What do they want? What do they get? Does education have therapeutic potential? Who should teach-the doctor, the nurse, the therapist? How can the general public be made more aware of arthritis? What are the charities doing? Are undergraduates taught rheumatology? Is the emphasis on conditions that they are likely to see as doctors? What methods are available? What is the evidence that they work? What do general practitioners learn about rheumatic complaints during vocational training? What should they know? How effective are the different forms of education in modifying subsequent behaviour? How should the rheumatologist continue rheumatological education?

I hope you will find the answers to some of these questions in the following chapters.

Department of Rheumatology,

The London Hospital,

PAUL W THOMPSON

Whitechapel,

London EI IBB

\section{Education: the need for a rethink}

Education is a continuing process for us all, or at least it should be. From the first enthusiastic steps as a new medical student to the quiet and measured tread of the retired it is something that we should all see as a compelling need. Mark Twain put it succinctly: soap and education are not as sudden as a massacre, but they are more deadly in the long run. And yet times are changing fast and there is ample evidence that all is not well in medical education. To quote Anderson $^{1}$ in a recent Green College lecture 'Irresistible forces are impelling us into an era of change and compelling the educators to re-think their responsibilities'.

The Christ Church conference of $1961^{2}$ led to far reaching changes in postgraduate education and to the wide dissemination of postgraduate centres, but we seem to have lost our way since then. Is postgraduate education as it now exists good value for money? Another Green College lecture sounded some doubt about this. Too much attention is being paid to vested educational interests and rigid require- ments for training and not enough to real needs. Perhaps it would be better to have a single national inspecting body as in Australia and the United States that accredits hospitals rather than individual posts and considers service provision as well as the educational facilities that exist. ${ }^{3}$

Clinical tutors need special skills and should be chosen because of these rather than arbitrarily because it is buggins turn as seems to happen at the moment. They need a much longer term in office and should be allotted adequate time in the working week to practise these skills. Because then they might have to sacrifice much of their private practice they should have adequate remuneration for it. This should later be reflected in their pensions so that they do not lose out by it. Proper resources are needed to employ people with a real commitment and talent for continuing education. ${ }^{4}$

The United Kingdom, as indeed are most Western countries, is going through a higher education crisis. Too few of the bright and intelligent are going forward to higher education and there is inequality of access to it and too few funds for it. ${ }^{5}$ There seems to be a lack of clear distinction between training and service elements, a lack of proper teaching, little educational training for teachers, and no clearly allotted time for training and teaching. ${ }^{6}$

Firstly, we need to identify the key decisions that have to be made. These have been clearly spelled out as: What is the desired change? Where should education take place? Who should do it? and How should it be done? ${ }^{7}$ Until we have clear agreement on these fundamental problems we will be unlikely to make adequate progress.

To start with the undergraduate, we may be choosing the wrong person too often to become the medical practitioner of the future. Too many medical schools dispense with the interview for likely candidates and yet there is evidence that a structured interview helps to sort out those who are unlikely to succeed and, conversely, those who are likely to do well. ${ }^{8}$ Too often the medical curriculum fails to instill into the medical student the same degree of commitment and responsibility for health for patients in the community as for hospital patients. 9 Too often students entering medicine with a high sense of vocation lose much of it by the time they qualify. At least in North America the education of undergraduates has placed more emphasis on the entitlements of their career than on the more selfless aspects of service to their patients. Senior doctors must set a good example by showing good practice as a role model. ${ }^{10}$ After qualifying, as was pointed out by the New York Commission on Graduate Medical Education, residency training must provide educational opportunities beyond practical clinical experience. ${ }^{11}$ The main implication for training and education is the provision of adequate time for study and careers advice. Present educational programmes need revision in the light of this. ${ }^{12}$ Far too many of our doctors in training are so exhausted by the long hours needed for 
clinical care that they have too little energy and motivation left over to devote to proper study. We are failing them badly by not ensuring that there are enough skilled people to do the work and allowing time for proper self improvement. Nor must we forget that there is a need for basic scientists as well as clinicians and that we need to integrate them into the training programme. ${ }^{13}$

When we turn to the training of general practitioners we must bear in mind that nearly a quarter of all consultations in primary care are about the rheumatic diseases. ${ }^{14}$ Yet rheumatology ranked 18th in the pecking order of medical specialties in which postgraduate education had been received by general practitioners. Less than a fifth had attended a rheumatology postgraduate course. ${ }^{15}$ Medicine, obstetrics, paediatrics, and dermatology were considered by them to be the most relevant hospital specialties for training for general practice. ${ }^{16}$ Are we giving them the education that they need? Whereas most consultants take part in teaching programmes, not nearly enough time is devoted to what general practitioners want. Teaching in small groups seems to be the best medium, with interchange between consultants and primary care doctors on shared cases. This has clearly been seen as the preferred way of teaching by many consultants, yet what did they actually give? They gave formal lectures, which most seem to agree is not the best way to teach. ${ }^{17}$ General practitioners clearly want their education done by their local consultant and not by visiting experts, ${ }^{18}$ and on a more informal basis where the opportunity for question and answer arises more easily.

What about consultants themselves? Few would disagree with the importance of keeping up to date with the latest knowledge and developments in the specialty. It is a duty both to patients, doctors in training, and the senior doctors' own sense of professional satisfaction to keep abreast of the advances that continuously occur. Indeed a continuing medical education programme has been shown quite clearly to effect changes in doctors' knowledge and behaviour, with subsequent improvement in patient care. ${ }^{19}$

And what of the patients themselves? Even in 1884 doctors were interested in the effect on patients' health of physical training. ${ }^{20}$

There have been many attempts at education of patients about arthritis. They seem to get most of their information, however, from the mass media and not always with the best results. ${ }^{21}$ Information booklets appear to be helpful, ${ }^{22}$ and education programmes aimed at enhancing self care capabilities have been shown to be effective. ${ }^{23}$ For the best results, however, education for patients needs to be aimed at individual instruction rather than using a more general approach. ${ }^{24}$ Lay leaders have been shown to teach arthritis self management techniques as effectively as professionals. ${ }^{25}$

Finally, what methods should we use for teaching? The use of 'high tech' equipment has proved disappointing if more emphasis is placed on the technology used rather than on the prime aim of the teaching itself. ${ }^{26}$ In other words it needs to be used more intelligently as an aid and not for its own sake.

The papers published in this supplement look at all these varying aspects. You may or may not agree with their conclusions but this at least is clear: education about rheumatology needs to be looked at with much more care and to be much better organised than hitherto. We are not being as efficient in our training at all levels as we should be. It is time to sit and think of how best we may improve ourselves. Nobody else is going to do it.

A K THOULD

1 Anderson W E K. Green College lectures: responsibility of the educator. BMF 1989; 298: $1699-701$.

2 Pickering G. Postgraduate medical education: the present opportunity and the immediate media. BMF 1962; i: 421-5.

3 Paton A. Christ Church conference on postgraduate education-25 years on BMF 1987; 294: 393-4.

4 Gray J A M. Continuing education: what techniques are effective? Lance 1986; ii: $447-8$.

5 Dean $M$. London perspective. Higher education; too few students, unequal access, no finance. Lancet 1990; 335: $100-1$.

6 Grant J, Marsden P, King R C. Senior house officers and their training. II. Perceptions of service and training. $B M F$ 1989; 299: $1265-8$.

7 Hubling J. Principles of health education. BMF 1984; 289: 1054-6.

8 Powis D A, Neame R L B, Bristow T, Murphy L B. The objective structured interview for medical student selection. BMF 1988; 296: 765-8.

9 Stuart K. Health for all: its challenge for medical schools. Lancet 1984; i: 441-2.

10 Dubrovsky S L. Coping with entitlement in medical education. $N$ Engl f Med 1986; 315: $1672-4$.

11 Delbanco T L. Wheeling and dealing with graduate medical education. Ann Interm Med 1986; 105: 961-2.

12 Grant J, Marsden P, King R C. Senior house officers and their training. I Personal characteristics and professional circumstances. BMF 1989; 299: 1263-5.

13 Arias M. Sounding board: training basic scientists to bridge the gap between basic science and its application to human disease. N Engl f Med 1989; 321: $972-4$.

14 Wood P H N. The challenge of arthritis. London: Arthritis and Rheumatism

15 Wright V, Hopkins R, Burton K E. What shall we teach undergraduates? $B M \mathcal{F} 1979$; i: 805-7.

16 Kelly D R, Murray T S. Twenty years of vocational training in the west of Scotland. BMF 1991; 302: 28-30.

17 Badley E M, Lee J. The consultant's role in continuing medical education of general practitioners: the case of rheumatology. BMJ 1987; 294: 100-3.

18 Wright $\mathrm{V}$. The consultant rheumatologist and postgraduate education. $B M \mathcal{F}$ 1983; 287: 1158-9.

19 Stross J K, Schumacher H R, Weisman M H, Spalding D M. Continuing medical education; changing behaviour and improving outcomes. Arthritis Rheum 1985; 28: 1163-7.

20 Anonymous. 100 Years ago. BMf 1984; 288: 1787.

21 Price J H, Hillman K S, Toral M E, Newell S. The public's perceptions and misperceptions of arthritis. Arthritis Rheum 1983; 26: 1023-8.

22 Sandler D A, Michell J R A, Fellows A, Garner S T. Is an information booklet for patients leaving hospital helpful and useful? BMF 1989; 298: 870-4.

23 Goeppinger J, Arthur M W, Baglioni Jr A J, Brunk S E, Brunner C M. A reexamination of the effectiveness of self-care education for persons with arthritis. Arthritis Rheum 1989; 32: 706-16.

24 Lorish C D, Parker J, Brown S. A quasi-experiment comparing an individual strategy with a routinised strategy. Arthritis Rheum 1985; 28: 1289-97.

25 Lorig K, Feigenbaum P, Regan C, Ung E, Chastain R L, Holman R. A comparison of lay-taught and professional-taught arthritis self-management courses. F Rheumatol 1986; 13: 763-7.

26 Golden W E, Friedlander I R. Inverse technology and medical education. Lancet 1987; i: 851-3. 